\title{
APRENDIZAGEM DA PRÁTICA DE ENSINO POR PARTICIPAÇÃO NA ESCOLA: CONTRIBUIÇÕES DO ESTÁGIO SUPERVISIONADO
}

\author{
LEARNING OF TEACHING PRACTICE THROUGH PARTICIPATION IN SCHOOL: \\ CONTRIBUTIONS OF THE STUDENT TEACHING
}

\section{APRENDIZAJE DE LA PRÁCTICA DE ENSEÑANZA POR PARTICIPACIÓN EN LA ESCUELA: CONTRIBUCIONES DE LA PASANTÍA SUPERVISADA}

Raquel Gomes de Oliveira*

\begin{abstract}
Resumo: A proposta deste artigo é mostrar que, por meio do conceito de Cognição Situada, podem existir parâmetros para a aprendizagem da prática de ensino docente, desde a formação inicial de professores. Características e consequências dessa aprendizagem serão apresentadas através dos resultados de uma pesquisa que objetivou verificar a contribuição para a elaboração de saberes docentes, a partir de uma proposta de Estágio Supervisionado que propôs a superação da sequência observaçãoparticipação-regência. A pesquisa foi realizada com licenciandos do $4^{\circ}$ ano do curso de Matemática de uma universidade paulista pública. Quando princípios da Cognição Situada foram utilizados para o desenvolvimento do Estágio Supervisionado, além da base de conhecimento para a docência apontada por Shulman (1986), os resultados apontaram para a necessidade de consideração do saber atitudinalafetivo como também um saber necessário à docência e consequente e efetiva prática de ensino.
\end{abstract}

Palavras-chave: Cognição Situada. Prática de Ensino. Formação de Professores. Estágio Supervisionado.

\begin{abstract}
The purpose of this article is to show that, through the concept of Situated Cognition, there may be parameters for learning the teaching practice, since initial teacher education. Characteristics and consequences of learning will be presented through the results of a survey that aimed to determine the contribution to the development of teacher knowledge, from a student teaching proposal that seeked over the observation-participation-regency sequence. The research was conducted with undergraduate students in the 4th year of mathematics teacher education at a public university of São Paulo. When principles of Situated Cognition were used for the development of the Student Teaching beyond the knowledge base for teaching pointed to by Shulman (1986), the results pointed to the need for consideration of attitudinal-affective knowledge as a necessary knowledge for teaching and effective consequent teaching practice.
\end{abstract}

Keywords: Situated Cognition. Teaching Practice. Teacher Education. Student Teaching.

Resumen: La propuesta de este artículo es mostrar que, por medio del concepto de Cognición Situada, pueden existir parámetros para el aprendizaje de la práctica de enseñanza docente, desde la formación inicial de profesores. Características y consecuencias de ese aprendizaje serán presentadas a través de los resultados de una pesquisa que objetivó verificar la contribución para la elaboración de saberes docentes, a partir de una propuesta de Pasantía Supervisada que propuso la superación de la secuencia

*Doutorado em Educação pela Faculdade de Educação da USP. Durante 16 anos foi professora de Matemática na Educação Básica e atualmente é professora responsável pelas disciplinas Didática e Estágio Curricular Supervisionado do Curso de Licenciatura em Matemática da FCT-Unesp. Email: raqueloliveira@fct.unesp.br 
observación-participación-regencia. La pesquisa fue realizada con licenciandos del $4^{\circ}$ año del curso de Matemáticas de una universidad paulista pública. Cuando principios de la Cognición Situada fueron utilizados para el desarrollo de la Pasantía Supervisada, además de la base de conocimiento para la docencia apuntada por Shulman (1986), los resultados apuntaron para la necesidad de consideración del saber actitudinal-afectivo como también un saber necesario a la docencia y consecuente y efectiva práctica de enseñanza.

Palabras-clave: Cognición Situada. Práctica de Enseñanza. Formación de Profesores. Pasantía Supervisada.

\section{Introdução}

O tema formação de professores está sendo considerado como um campo de investigação científica que tem possibilitado a realização de pesquisas (ZEICHNER, 1987, 2002; KINCHELOE, 1993; SANTAELLA, 1998; GARCIA BLANCO, 2000; SCHÖN, 1983; SACRISTAN, 1991; PÉREZ-GOMEZ, 2000) que se referem a diferentes perspectivas para essa formação: a Perspectiva Acadêmica, a Perspectiva Técnica, a Perspectiva Prática e, por último, a Perspectiva de Reflexão da Prática para a Reconstrução Social.

O fato de serem perspectivas diferentes, tanto no discurso teórico quanto ao desenvolvimento prático desta formação, não impediu que se pudesse destacar um interesse comum para todas elas, identificado com a busca por respostas às questões: o que deve saber um professor? Como e onde acontece a elaboração desse saber?

Buscar responder a essas questões tem promovido reflexões e questionamentos sobre situações contraditórias. Geralmente, essas situações têm origem na formação de professores subsidiada por perspectivas que desconsideram condições e necessidades das escolas, também reconhecidas como espaço de formação de saberes docentes em documentos legais como, por exemplo, na Resolução CNE/ CP 01/2002 e no Parecer CNE/CP 09/2001.
A escola também, enquanto um contexto (LACASA, 1994) do qual emanam formações e que recebe todas as influências do contexto maior (a sociedade e sua cultura) em que está inserida, não se sintoniza mais com os princípios da racionalidade técnica, muito menos com os profissionais da Educação que nela foram inicialmente formados. (BRASIL, 2011, p.48).

Todo o tipo de diversidade (econômica, de gênero, étnica, cultural, religiosa...) encontrado na escola exige profissionais da Educação cada vez menos conteudistas e autômatos (no sentido de serem aplicadores ou fiéis receptores de regras de condutas idealmente elaboradas para a escola, de regras acordadas por outros profissionais, distantes do contexto escolar atual). Tal contexto é caracterizado por sentidos de individualidade e de autonomia de cada escola, que muitas vezes expressam a necessidade de imposição de um "ideal pedagógico” próprio e característico daqueles que há muito estudam, professam, imaginam, debatem, opinam sobre a escola, seu cotidiano, seus habitantes, mas que, por inúmeras razões, não participam da dinâmica cotidiana desta escola. (BRASIL, 2011, p.48).

A crítica ao conteúdismo, no entanto, não ignora nem minimiza a necessidade de conhecimentos ou de saberes. Ao contrário, a linha do tempo da formação docente, polarizada pelo conhecimento inicial para a 
docência e a prática de ensino em sala de aula, é composta por conhecimentos considerados como gerais e específicos como, por exemplo, o conhecimento do próprio conteúdo, o conhecimento pedagógico do conteúdo e o conhecimento curricular do conteúdo, analisados por Shulman $(1986,1987)$.

Mesmo que Shulman $(1986,1987)$ tenha esclarecido como se originam esses conhecimentos, pesquisas que objetivam buscar outras origens e outros parâmetros se fazem necessárias para embasar dois marcos considerados indispensáveis à formação inicial e contínua do professor: o conhecimento necessário para ensinar (conhecimento do professor: conceitualização, domínio e estrutura) e o processo de aprender a ensinar (aprendizagem do professor especialista: conceitualização e caracterização do processo de ensino e aprendizagem de cada disciplina).

É no sentido de dar referências para a aprendizagem da prática pedagógica docente que este artigo procurará evidenciar parâmetros e implicações da Cognição Situada para que essa prática alcance sua intencionalidade, ou seja, levar o aluno a aprender. (HIRST, 2001). Para isto, serão analisados os resultados de uma pesquisa realizada com licenciandos (futuros professores), entendidos na pesquisa como alunos que estão aprendendo a prática de ensino de Matemática, durante o desenvolvimento do Estágio Curricular Supervisionado. O objetivo da pesquisa era verificar a contribuição para a elaboração de saberes docentes de uma proposta de Estágio Supervisionado que buscou a superação da sequência observação-participação-regência, por ações embasadas na perspectiva de aprendizagem apresentada pela Cognição Situada.

\section{Sobre conceito de cognição situada e suas potencialidades para a aprendizagem da prática de ensino desde a formação inicial de professores}

As proposições de Shulman (1986, 1987) sobre a constituição de uma base de conhecimento para a docência estão suscitando o interesse pela origem da aprendizagem deste conhecimento, discutida, por exemplo, por Sfard (1998).

Se cremos que aprendemos por aquisição ou por participação (SFARD, 1998) levou a repensar e a reelaborar o conceito de escola, que, quando identificado com o conceito de contexto sociocultural (LACASA, 1994), permitiu que os vários processos de aprendizagem que nele acontecem, por exemplo, os processos de aprendizagem da prática de ensino por estagiários, pudessem ser identificados como processos participativos situados em contextos nos quais o aprendiz se relaciona com o objeto do conhecimento. (LAVE, WENGER, 1991).

Na aprendizagem situada, o aluno não é um receptor passivo do conhecimento que está no mundo e muito menos constrói conhecimento centrado em si, à parte das situações que o rodeiam. Ao contrário, engajando-se em uma comunidade de prática, ele age sobre as situações e com as situações acarretando recíproca mudança. (XXXXX, 2001, p.43).

Uma comunidade de prática é um conjunto de relações entre pessoas, atividades e mundo, sobretudo em uma relação tangencial e de envolvimento com outras comunidades de prática. Uma comunidade de prática é uma condição intrínseca para a existência do conhecimento, no mínimo porque esta fornece o suporte de interpretação necessário para dar sentido a sua tradição. (LAVE; WENGER, 1991, p. 98). 
Quando a aprendizagem é entendida, de acordo com Lave; Wenger (1991), como engajamento em uma comunidade de prática, é possível adjetivá-la como situada porque remete a pensamentos e ações que acontecem em um determinado espaço, em um determinado tempo, que são em si fontes de significados e significações, em que ocorrem práticas sociais marcadas por participação e envolvimento de pessoas e que, portanto, vão oportunizar o desenvolvimento de significados e de significações atrelados a essas práticas contextuais.

Para a Cognição Situada, aprender é participar. Uma participação que tem início em ações periféricas através de atividades reais e que vai evoluindo para ações centrais que caracterizam a aprendizagem em questão.

Lave e Wenger (1991) associam a aprendizagem por Cognição Situada ao processo denominado de Participação Periférica Legítima (PPL). Este processo possui como característica principal considerar que o ponto de partida para a aprendizagem é a participação social em um determinado grupo. Grupo que não se restringe ao conceito de vizinhança, de proximidade, mas sim de ser o continente de determinados saberes, práticas e relações.

Lave e Wenger (1991) descreveram o processo de Participação Periférica Legítima em comunidades de prática, precisamente na relação entre peritos e novatos ou entre mestres e aprendizes ${ }^{1}$. Nessa descrição encontram-se fundamentações, pressupostos e modos de ocorrer uma atividade situada. O que se depreende dessa descrição é que a natureza da aprendizagem é de caráter relacional

\footnotetext{
${ }^{1}$ Lave e Wenger (1991) encontraram os pressupostos de Cognição Situada especificamente em 5 grupos: parteiras indígenas mexicanas, marinheiros norte-americanos, alfaiates africanos, açougueiros e alcoólatras abstêmios.
}

entre o aprendiz, o objeto de conhecimento e o contexto onde a aprendizagem ocorre.

Trabalhos sobre a Cognição Situada (LAVE, WENGER, 1991; BROWN et al, 1989), considerada como um marco para processos pedagógicos em situações escolares (GARCIA BLANCO, 2000; GARCIA E SANCHEZ, 2002; LAMPERT, 1985, 1990; MATOS, 2000), tornaram-na possível como uma referência de aprendizagem de saberes tanto para a formação inicial quanto contínua de professores.

Na formação de professores, é possível afirmar que o conceito de Cognição Situada, precisamente o entendimento da natureza relacional da aprendizagem, pode ser tomado como referência para a aprendizagem de saberes docentes à medida que o professor da Educação Básica passou a ser considerado também como produtor de conhecimento em um contexto, neste caso a escola, que apresenta condições e necessidades específicas acarretando outros princípios para o desenvolvimento, por exemplo, do Estágio Supervisionado a ser realizado por futuros professores.

Desse modo, necessitaram ser revistos modelos de estágios baseados em princípios da racionalidade técnica, na qual se pressupunha que o saber era oriundo da universidade e deveria ser aplicado na escola. Geralmente, essas aplicações aconteciam em momentos específicos, como durante o tempo destinado à regência do estagiário e por meio de projetos de intervenção elaborados sem a colaboração do professor da escola, sem vínculo com as demandas da escola.

À medida que historicamente a escola passou a ser reconhecida como uma possível comunidade de prática (prática de leitura, de escrita, de oralidade, de matematização, de esporte, de socialização etc.), princípios da racionalidade técnica para a formação inicial 
de professores começaram a ser questionados, principalmente em função de que os contextos escolares começaram a conflitar com estes princípios, como, por exemplo, aquele que supunha como alicerce da aprendizagem da prática de ensino, pelo futuro professor, as ações de observação e imitação, ou seja, "Quem não sabe, ao observar quem sabe, irá assim aprender”.

Contrariamente à aprendizagem por observação e imitação, o princípio da Cognição Situada, segundo o qual “... a atividade passa a ser o centro do processo de aprendizagem, considerada como uma forma de compreender o próprio contexto no qual se origina” (Garcia Blanco, 2000, p. 60), apresenta implicações para o programa de formação dos professores, no que se refere aos conteúdos, como também para as escolhas metodológicas para o trabalho pedagógico com esses conteúdos.

Diante destas considerações, como oportunizar o desenvolvimento da Prática de Ensino e do Estágio Supervisionado que se coadune com os princípios e conceitos derivados da Cognição Situada, como os de Comunidade de Prática e de Participação Periférica Legítima?

Conforme as Diretrizes Nacionais para a Formação de Professores (Resolução CNE/CP 01/2002), todo licenciando deverá desenvolver o estágio curricular em escola de Educação Básica. Portanto, é de se esperar que este desenvolvimento, que possui como foco saberes da prática de ensino, seja confrontado com o uso de ferramentas conceituais próprias daquele ambiente escolar e de como estas ferramentas são utilizadas na prática cotidiana. Assim, inserir-se na escola é comprometer-se com o sistema de valores e de elementos daquela comunidade escolar, entendendo que as ações ali realizadas não se apresentam unicamente como adaptativas porque a transformação ocorre tanto para o indivíduo, como para a comunidade escolar.

Por exemplo, em uma aula de Matemática, a relação entre o professor experiente e o futuro professor, na condição de estagiário, não é decorrente do desenvolvimento de ações, externamente planejadas e significadas, para posteriormente serem aplicadas. Contrariamente a isso, a relação mestre e aprendiz tem como origem situações de sala de aula que propiciam ações de reflexão e investigação dos acontecimentos daquela sala de aula, à medida que se compreende e se aceita que situações podem regular pensamentos e ações: a relação mestre e aprendiz é sustentada tanto pelo contexto como pelo objeto da relação (um conteúdo, um problema a ser resolvido, uma pesquisa temática, uma tarefa, uma atividade...), em outras palavras, uma vivência.

Sobre se aprendemos por aquisição ou por participação, concordamos com Sfard (1998) sobre não se ter justificativa para a escolha de uma metáfora ou outra para a aprendizagem. Acreditamos que participar só tem sentido quando se procura algo e que a participação é sobre algo. Deste modo, uma relação dialética entre obter e participar se instaura.

A preocupação com a elaboração de saberes docentes, gerais e específicos, desde a formação inicial, na pesquisa que realizamos, não subestimou uma concepção de aprendizagem em relação à outra.

\section{De quando e como foi realizada a pesquisa}

Em 2006 realizamos uma pesquisa-ação que transcorreu sob uma abordagem qualitativa e que propôs a superação da sequência observação-participação-regência, com 17 licenciandos do $4^{\mathrm{a}}$ ano de um curso de 
Licenciatura em Matemática de uma universidade paulista pública. O quadro 1 representa a dinâmica das atividades realizadas durante o Estágio Supervisionado, considerando-se a pesquisa-ação e a escola como um contexto.

Quadro 1: Dinâmica para o desenvolvimento do Estágio Supervisionado

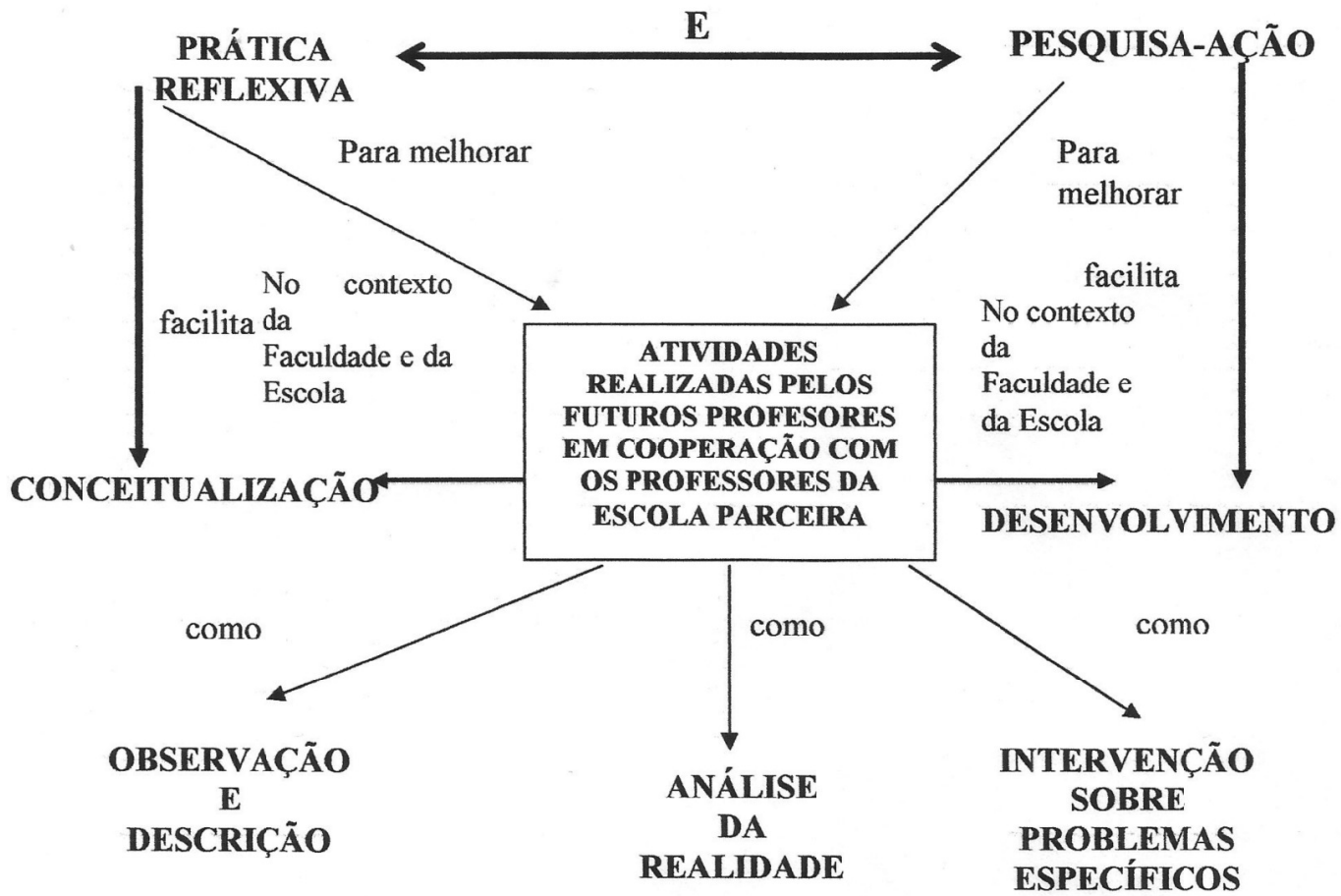

Fonte: Adaptação do modelo de GAIRIN e GIMENO, 1995 apud SANTAELLA, 1998, p. 172

Com a proposta de superação da sequência observação-participação-regência esperava-se verificar contribuições para a aprendizagem de saberes de futuros professores de Matemática relacionados à prática de ensino.

O planejamento dos percursos, o desenvolvimento, a análise e discussão dos dados e formulações posteriores fundamentaram-se na base conceitual de três domínios que se aproximam e dialogam: a pesquisa-ação, o trabalho cooperativo e a Cognição Situada.

A pesquisa-ação por permitir o diagnóstico de um problema prático ou a tomada de consciência (THIOLLENT, 1994) do que se quer melhorar ou resolver, sendo que o conhecimento gerado pela pesquisa não é considerado seu objetivo principal (ELLIOTT, 1993, TRIPP, 2005), o que justificou a intervenção, a direção e o redirecionamento das ações por parte da pesquisadora. O trabalho cooperativo porque nele a aprendizagem “... é definida por um conjunto de processos que ajudam as pessoas a interagirem juntas com a intenção de realizarem um objetivo ou desenvolverem um produto final, que é normalmente um conteúdo específico". (PANITZ, 1996, p. 1). E, por fim, a Cognição Situada porque explicações e elucidações fornecidas a partir de seu referencial teórico vieram ao encontro da proposta de Estágio que se buscou estabelecer e conhecer através da pesquisa realizada: 
o fato de se ter o Estágio Supervisionado como processo investigativo participativo e a hipótese da comunidade escolar como uma possível comunidade de prática contribuíram para isto.

Os estagiários foram apresentados, todos ao mesmo tempo, em uma reunião realizada em uma escola que foi denominada de escola parceira para o desenvolvimento de trabalho cooperativo com professores da instituição escolar. Esse trabalho tinha como objetivo propiciar aos estagiários oportunidades de desenvolver capacidades investigativas, experienciando metodologias de aprendizagem ativa, de resolução de problemas, bem como de trabalho individual e em grupo que contribuíssem para a construção de relações novas e significativas tanto para os acadêmicos, como para a comunidade escolar. O número de 17 estagiários e 4 professores de Matemática da escola, que aceitaram participar da pesquisa, possibilitou que fossem criados 4 grupos de trabalho, ficando cada grupo sob a responsabilidade de um professor de Matemática da escola.

Já com o objetivo de explicitar as expectativas sobre o desenvolvimento do Estágio Supervisionado, bem como os aspectos apontados como positivos e negativos pelos participantes e implicações da pesquisa para futuros trabalhos, realizaram-se entrevistas na escola com o diretor, o coordenador pedagógico e os professores de Matemática, os quais receberam os estagiários em suas aulas. Na universidade foram aplicados questionários para os estagiários e para a professora responsável pela disciplina que comportava as horas de estágio a ser realizado. Os dados da pesquisa também tiveram origem na observação participante da pesquisadora junto às aulas na faculdade e aos trabalhos desenvolvidos na escola parceira.
A partir da transcrição das entrevistas, das respostas aos questionários e da observação da pesquisadora junto às aulas da faculdade, houve a triangulação dos dados, possibilitando a elaboração de categorias que permitiram a realização da descrição analítico-interpretativa desses dados.

\section{Sobre a realização do Estágio Supervisionado e a elaboração de saberes da prática de ensino}

O objetivo da pesquisa era verificar a contribuição, para a elaboração de saberes docentes, de uma proposta de Estágio, ao se propor a superação da sequência observação-participação-regência, por ações embasadas na perspectiva de aprendizagem apresentada pela Cognição Situada.

No entanto, o que se concluiu das entrevistas e das respostas das professoras parceiras e por suas expectativas em relação ao desenvolvimento do Estágio é que o impedimento maior para sua realização, que implique elaboração do saber sobre a prática de ensino, não está nas ações históricas de observar, participar e reger aulas. Ao contrário, está no modo com estas ações acontecem. Isto porque observar, participar e reger solitariamente é muito distinto da observação, participação e regência sustentados pelo trabalho em grupo e, sobretudo, pela cooperação com o professor experiente. Assim, as atividades de observar, de participar e de reger aulas oriundas de diagnóstico, de planejamento, de investigação, de reflexão que se apresentam em termos do porquê, para que e para quem interessam tais atividades apresentam-se com distinção.

Analisando os dados foi possível afirmar que os grupos de trabalho compostos por estagiários e seus respectivos professores parceiros vivenciaram etapas que, segundo Tripp (2005), caracterizam um ciclo da pesquisa-ação: 
planejamento, desenvolvimento, descrição e avaliação com o objetivo de melhorar a prática implicando reelaborar e aprender saberes progressivamente enquanto o processo ocorre. Nega-se, portanto, a sequência de ações na qual primeiro se observa, depois participa e depois rege aulas.

\begin{abstract}
"Durante as aulas da professora P3 desenvolvemos um trabalho paralelo com os alunos das Olimpíadas, ministramos aulas de exercícios e plantão de dúvidas. Fizemos correção de trabalhos e reforço para os alunos com dificuldades em entenderem o conteúdo. Creio que nestas situações tivemos um papel fundamental para o desenvolvimento da aprendizagem desses alunos, trabalhando de forma investigativa e reflexiva." (Estagiário do Grupo 3).
\end{abstract}

Quanto aos saberes necessários à docência, elucidados, por exemplo, por Shulman (1986,1987), Schön (1983), Zeichner (1987, 2002), Tardif (2002), Perrenoud (2002), os dados da pesquisa permitiram concluir que a vivência do ciclo de uma pesquisa-ação no contexto escolar implicou a experiência do princípio de participação periférica legítima no cotidiano da sala de aula (LAVE e WENGER, 1991). Já a participação periférica legítima necessitou de saberes iniciais, ou seja, como exemplo, o saber do conteúdo matemático foi imprescindível para a construção e reelaboração de outros saberes docentes.

Inicialmente, em muitos casos, os saberes do conteúdo de Matemática, de cada classe estagiada, os saberes sobre como trabalhar pedagogicamente esse conteúdo, utilizados na prática de ensino pelos estagiários estavam se encaminhando para serem os mesmos saberes, com pequenas variações, de quando eram alunos na Educação Básica.

No entanto, os dados revelaram que, devido ao trabalho conjunto com o professor de Matemática da escola, os estagiários conseguiram elaborar saberes para a prática de ensino, que possuíam a base de conhecimento proposta por Shulman (1986), mas que se tornou efetiva diante de uma prática de ensino situada, que ocorreu por participação do estagiário considerando necessidades e condições de cada aula estagiada, ou seja, uma prática de ensino relacionada com pressupostos da Cognição Situada.

De modo geral, o desenvolvimento do Estágio Supervisionado proporcionou aos estagiários refletir sobre seus saberes matemáticos e aprender sobre a transposição ou maneiras de trabalhá-los nas situações de sala de aula.

Desenvolver o Estágio Supervisionado a partir de condições e necessidades das aulas estagiadas permitiu que os estagiários refletissem sobre a natureza da Matemática em termos de uma construção de saberes permeada por necessidades, capacidades e condições humanas que se apresentam pela história do homem e, nesse sentido, impregnada de raciocínios não lineares, mas sim caracterizados por dúvidas, conjecturas, refutações, erros, contradições.

Especificamente sobre o saber para a prática de ensino, os estagiários afirmaram ter aprendido e constatado a existência das diversas representações que os alunos de diferentes séries estagiadas constroem sobre um mesmo conceito matemático, em diferentes situações, e o modo como constroem essas representações e conseguem chegar ou não a um acordo para uma representação comum, no caso da Matemática, sua linguagem. Nesse sentido, foi significativa para eles a ciência de que é preciso haver ambientes de discurso matemático e maneiras para se chegar a ele em sala de aula.

O saber dos estagiários para a prática de ensino, pode-se afirmar, foi elaborado no desenvolvimento do Estágio Supervisionado 
porque tiveram oportunidades de confrontar suas experiências, crenças e expectativas quanto à docência em situações reais de sala de aula com o apoio do professor experiente, refletindo sobre os saberes dos professores de Matemática, quando atuam no contexto escolar, buscando ciência não somente dos saberes necessários para ensinar Matemática, mas como variam esses saberes, como se articulam e em quais situações. Esta elaboração do saber por parte dos estagiários pode ser reconhecida em alguns exemplos de respostas à questão 7 : "O que você considera ter aprendido com 0 desenvolvimento das horas de Estágio?”

"[...] me trouxe bastante esclarecimento sobre o assunto e também aprendi muito com a professora P1 em como ministrar uma aula, organização, disciplina, foi muito bom." (Estagiário A do Grupo 1).

"Aprendi que a realidade escolar é bem diferente daquilo que imaginamos quando resolvemos fazer Licenciatura em matemática, pois vamos nos deparar com alunos desinteressados, outros com problemas familiares e o professor terá que saber controlar todas essas situações." (Estagiário B do Grupo 1).

"Contribuiu para minha formação acadêmica, pois tive uma visão da sala de aula e diferentes formas de ensino." (Estagiário A do Grupo 2).

"Lidar com diferentes situações que possam surgir, aprendi também a desenvolver atividades investigativas e aplicá-las de forma a alcançar objetivos pré-determinados." (Estagiário C do Grupo 2).

"Que teremos que ter muito amor e força de vontade, envolvimento mesmo com nossas práticas de Educador. A educação pública não é perfeita, há muito mais dificuldade que se pensa, mas tudo pode ser superado se realmente amamos o que fazemos e nos sentimos responsáveis pelo que será (o futuro) de cada "carinho" que encontramos em nossa prática docente." (Estagiário D do Grupo 2).

"Muita coisa. Além de relembrar alguns conceitos, aprendi muito com os alunos, principalmente que nós, adultos, nos atemos muito a conceitos e estruturas enquanto eles são espontâneos e muitas vezes encontram soluções mais simples e mais rápidas para os problemas." (Estagiário A do Grupo 3).

"Dar aulas." (Estagiário B do Grupo 3)

"Que é preciso mudar a forma com que as aulas são passadas aos alunos. É necessário como pessoa estar sempre aberto a coisas novas e ao diálogo." (Estagiário B do Grupo 4).

"Relacionar-se com professores e alunos, conhecer a realidade da escola pública, o que desperta vontades e ideias para um futuro profissional próximo." (Estagiário C do Grupo 4)

"Como apresentar a matéria para os alunos, de modo prático, de acordo com a realidade dos mesmos, maneiras ou formas alternativas de ensinar." (Estagiário D do Grupo 4)

De acordo com a análise descritivo-interpretativa, foi possível inferir que outro saber docente poderia ser considerado desde a formação inicial do professor para compor a base de conhecimento docente: o saber atitudinal-afetivo.

Quando se consideraram princípios da Cognição Situada como referência teórica pra a proposta de Estágio Supervisionado, a relação entre a pessoa experiente em uma determinada prática e o aprendiz desta prática foi entendida como contribuinte para referenciar a formação inicial de professores no que se refere aos saberes sobre a prática de ensino que poderiam surgir desta relação.

Nesse sentido, junto aos professores da escola foram observadas atitudes profissionais, na prática de ensino e na orientação da prática de ensino dos estagiários, que não 
se identificam com os saberes do conteúdo, com o saber pedagógico, nem com o saber curricular. Nessas atitudes estava explícita a componente afetiva para o saber da prática de ensino e que foi reafirmada nas entrevistas dos professores:

"Se você colocar amor na sua profissão, empenho, dedicação, coragem, ir com aulas preparadas, sabendo que cada dia é um dia, que você vai encontrar ali naquela sala diferentes crianças, que vieram de diferentes famílias, sabe, com diferentes problemas, com misérias mil, que a gente sabe, que são crianças que para você conseguir ensinar Matemática, primeiro você tem que chegar, ganhar o amor, passar amor para essa criança para você conseguir poder ensinar a Matemática." (Professora P1).

"Porque não é só o conteúdo, né? A gente não pode só dar o conteúdo... Às vezes a gente que comentar sobre o que acontece [...]" (Professora P2).

"Primeira pergunta era falar se ele (o estagiário) gosta do que ele faz. Se ele não gosta é para ele mudar de profissão. Agora se ele gosta... Porque quando você gosta, você consegue passar isto para os alunos que você está ensinando, porque você ama o que está fazendo. Sempre tem isso [...] Então fica fácil para dar aula." (Professora P3).

"Porque a gente tem experiência, a gente tem vinte e nove anos, então tem bastante dica, bastante jeito de pegar o aluno (o aluno da Educação Básica), ir ao encontro dele, ser humilde ao aluno. O Professor, antes de tudo, é um educador. Se ele é um educador ele tem que ter educação. Eles me respeitam tanto [...] Você pensa que é dia de prova, mas é o ambiente normal da classe." (Professora P4).

Encontrar, nas falas dos professores parceiros, aspectos atitudinais e afetivos sempre vinculados às situações escolares possibilitou pensar na necessidade de que, mesmo sendo saberes que possam ter uma origem subjetiva ou no modo como cada um se relaciona com a prática de ensino, estes saberes poderiam ser estudados com maior clareza na intenção de também serem constituidores curriculares de uma base de conhecimento para a docência, tal como a proposta por Shulman (1986).

\section{Considerações finais}

A Resolução CNE/CP 01/2002 não apresenta contradição textual quanto aos princípios e objetivos para a Educação Básica. Tudo se articula e corresponde ao que deveria ser e vir a tornar-se um profissional da Educação, do mesmo modo que é explícito o significado da escola como local de trabalho e também de formação deste profissional.

No entanto, desenvolver uma pesquisa na formação de professores de Matemática, especificamente relacionada à aprendizagem da prática de ensino durante o Estágio Supervisionado, permitiu afirmar que legalmente o expressivo aumento das horas de Prática de Ensino, totalizando 800 horas a serem desenvolvidas desde o início do curso, que contemplem 400 horas de Estágio Supervisionado, a partir da segunda metade do mesmo, tem se limitado a parâmetros quantitativos, revelando uma contradição quanto aos objetivos e princípios educacionais encontrados na própria legislação. Para muitos docentes, tanto das licenciaturas quanto das escolas da Educação Básica, não é clara e muitas vezes nem existe a distinção entre quais atividades compõem a Prática de Ensino e em quais lugares esta pode ser desenvolvida e quais atividades compõem o Estágio Supervisionado que, legalmente, só pode ser desenvolvido em escola e sob a supervisão de um professor habilitado na área de realização do Estágio Supervisionado. 
A ausência da institucionalização entre universidade e escola para a efetivação da dimensão sobre a prática de ensino na formação de professores, juntamente com as reformas top down ${ }^{2}$, que não ecoam as vozes de seus principais vetores, os professores das escolas da Educação Básica, asseguram as seguintes indagações:

- Como esperar que a escola assuma, entre outras funções que vem assumindo, uma efetiva participação na formação inicial dos professores, sem que existam condições estruturais e funcionais para isto?

- O que poderia originar o tempo comum para a parceria escola-universidade que se sobressaísse à boa vontade dos participantes deste tipo de trabalho?

- Supondo-se e defendendo-se que saberes dos professores que estão na Educação Básica e que o seu tempo de experiência são significativos para sua formação inicial, por que os professores da Educação Básica não possuem, em sua carga horária, horas-aulas destinadas ao trabalho conjunto com futuros professores e com professores universitários?

- Seria a resposta à questão acima uma forma de conscientização dos professores da Educação Básica sobre a responsabilidade que lhes cabe no que se refere à formação inicial de futuros colegas de profissão?

- A tomada de consciência desta responsabilidade possibilitaria o desenvolvimento de atitudes para além do que hoje se denomina professor reflexivo e professor pesquisador de sua prática?

\footnotetext{
${ }^{2} \mathrm{O}$ tipo top down de reforma, não somente na Educação, é também conhecido como reforma de "cima para baixo” e tem como principal característica a avaliação de necessidades e o planejamento de ações por pessoas distantes de locais e situações nas quais essas ações serão implementadas.
}

A ausência de institucionalização do espaço comum para uma efetiva parceria entre escola-universidade, no que se refere à dimensão prática das Licenciaturas, que está obrigatoriamente articulada a sua dimensão teórica, não desmerece o que se conseguiu com este estudo.

A historicidade do Estágio Supervisionado no Brasil confunde-se com a própria história da formação de professores, o que tem como consequência o fato de que a concepção de Estágio Supervisionado reflete e interfere nas características de formação de professores em tempos e espaços definidos. Contudo, essa mesma historicidade mostra que a aprendizagem sobre a prática de ensino é o conteúdo do Estágio Supervisionado.

$\mathrm{O}$ alcance do objetivo da pesquisa possibilitou identificar contribuições do desenvolvimento do Estágio Supervisionado para a elaboração de saberes docentes para essa prática de ensino.

Quando se buscou superar a sequência observação-participação-regência, acreditando que essa superação deveria ser alicerçada por referenciais teóricos e práticos, nos quais não se presume uma aplicação linear dos primeiros nos segundos, observou-se que a questão não é negar as ações de observar, participar e reger aulas. Ao contrário, essas ações referendadas por princípios da Cognição Situada confirmaram o Estágio Supervisionado como campo formativo de saber docente, especificamente o saber da prática de ensino. Assim, pode-se concluir que existem possibilidades de desenvolvimento de saberes docentes através do Estágio Supervisionado em que este não seja mais entendido como elemento emblemático de separação entre teoria e prática na formação de professores. 


\section{Referências}

BRASIL. Lei de Diretrizes e Bases da Educação Nacional. Lei ${ }^{\circ} 9394$ de 20 de Dezembro de 1996. Diário Oficial da União, Brasília.

BRASIL; MEC.CNE/CP. Parecer $\mathbf{n}^{0} 09$ de 08 de Maio de 2001. Disponível em http:// portal.mec.gov.br/sesu/ . Acesso em 20 de Abril de 2004.

. Resolução n ${ }^{\circ} 01$ de 18 de Fevereiro de 2002. Disponível em http://portal.mec. gov.br/sesu/ . Acesso em 20 de Abril de 2004.

BROWN, J. S.; COLLINS, A.; DUGUID, P. Situated Cognition and the Culture of Learning. Educational Researcher, n. 18, p. 32-42, 1989.

ELLIOTT, J. Recolocando a pesquisaação em seu lugar original e próprio. In: GERALDI, C; FORENTINI, D.; PEREIRA, E . M. (Orgs.). Cartografias do trabalho docente: professor(a)-pesquisador(a). Campinas: Mercado de Letras, 2003.

GARCIA BLANCO, M. M. El Aprendizaje Del Estudiante para profesor de matemática desde la naturaleza situada de la cognición: implicaciones para la formación inicial de maestros. In: CORRAL, C. Y ZURBANO, E. (Eds). Propuestas metodológicas y de evaluación en la formación inicial de los profesores del área de didáctica de la matemática. España: Universidad de Oviedo, 2000.

GARCIA, M; SANCHEZ, V. Una propuesta de formación de maestros desde la educación matemática: adoptando una perspectiva situada. In: CONTRERAS, L. C. Y BLANCO, L. J. Aportaciones a la formación inicial de maestros en el área de matemáticas: una mirada a la práctica docente. Universidad de Extremadura, Servicio de Publicaciones, 2002.

HIRST, P. H. What is teaching? Journal of Curriculum Studies. v. 3, n. 1, p. 5-18, 1971. Trad.: POMBO, Olga (2001). Disponível em: http://www.educ.fc.ul.pt/ docentes/opombo/hfe/cadernos/ensinar/ hirst.pdf. Acesso 28/05/2014

KINCHELOE, J. L. A Formação do professor como compromisso político: mapeando o pós-moderno. Porto Alegre: Artes Médicas, 1997.

LACASA, P. Aprender en la escuela, aprender en la calle. Madrid: Aprendizaje Visor, 1994.

LAMPERT, M. When the problem is not the question and the solution is not the answer: mathematical knowing and teaching. American Educational Research Journal, 27 (1), p. $29-63,1990$

How do Teachers manage to teach? Perspectives on Problems in Practice. Harvard Educational Review, 55, p. 178 194, 1985.

LAVE, J.; WENGER, E. Situated learning: legitimate peripheral participation. Cambridge University Press, 1991.

MATOS, J. F. L. Aprendizagem e prática social. contributos para a construção de ferramentas de análise da aprendizagem matemática escolar. In: PONTE, J. P; SERRAZINA, L. (Org.). Educação matemática em Portugal, Espanha e Itália. Actas da Escola de Verão- 1999. Seção de Educação Matemática da Sociedade Portuguesa de Ciências de Educação, 2000.

NÓVOA, A. Formação de professores e profissão docente. In: NÓVOA. A. (Org). Os professores e a sua formação. Lisboa: Publicações Dom Quixote. Instituto de Inovação Educacional, 1997. 
. Relação escola-sociedade: “novas respostas para um velho problema”. In: SERBINO, R. V. et al. (Orgs). Formação de professores. São Paulo: UNESP, p. 17-36 1996.

PANITZ, T. A definition of collaborative vs cooperative learning. http://www. city.londonmet.ac.uk/deliberations/collab. learning/panitz2.html, acesso 20/07/2005.

PÉREZ-GÓMEZ, A. Ensino para a compreensão. In: GIMENO SACRISTÁN, J.; PÉREZ-GÓMEZ, A. Compreender e transformar o ensino. Porto Alegre: Artmed, 2000.

PERRENOUD, P. A formação de professores no século XXI. In: PERRENOUD, P. (Org.). As competências para ensinar no século XXI: A formação dos professores e o desafio da avaliação. Porto Alegre: Artmed, 2002

PIMENTA, S. G. O estágio na formação de professores: unidade teoria e prática? São Paulo: Cortez, 2002

SACRISTAN, J. G. Consciência e acção sobre a prática como libertação profissional dos professores. In: NÓVOA, A. (Org.). Profissão professor. Lisboa: Livros Horizonte, 1991.

SANTAELLA, C. Formación para la profesión docente. Grupo Force y Grupo Editorial Universitario, 1998.

SCHÖN, D. A. The reflective practitionerhow professionals think in action. New York: Jossey Bass, 1983

SFARD, A. On two metaphors for learning and the dangers of choosing just one. Educational Researcher, vol. 27, $\mathrm{n}^{\mathrm{o}}$ 2, $\mathrm{p}$. 4-13, 1998.
SHULMAN, L. S. Knowledge and teaching: foundations of the new reform. Harvard Educational Review, 57 (1), p. 1 - 22, 1987 . Those who understand: knowledge growth in teaching. Educational Researcher, 15 (2), p. 4 - 14, 1986.

TARDIF, M. Saberes docentes e formação profissional. Petrópolis: Vozes, 2002

THIOLLENT, M. Metodologia da pesquisa-ação. São Paulo: Cortez, 1994.

TRIPP, D. Pesquisa-ação: uma introdução metodológica. Educação \& Pesquisa, 31 (3), p. 443-466, Set/Dez/ 2005. Disponível em http://www.scielo.br , 15/05/2006.

ZEICHNER, K. M. A pesquisa-ação e a formação docente Voltada para a justiça social: um estudo de caso dos Estados Unidos. In: PEREIRA, J. E. D.; ZEICHNER, K. (Orgs). A Pesquisa na formação e no trabalho docente. Belo Horizonte: Autêntica, 2002.

ZEICHNER, K; LISTON, D. Teaching students teacher to reflect. Harvard Educational Review, 57 (1), p. 1-22, 1987. 